\title{
TEMPERATURE DEPENDENCE OF DELAYED LIGHT EMISSION IN THE 6 to 340 MICROSECOND RANGE AFTER A SINGLE FLASH IN CHLOROPLASTS
}

\author{
P. JURSINIC* and GovindJEE** \\ Department of Physiology, Biophysics and Botany, University of Illinois, Urbana, IL 61801, U.S.A.
}

\author{
(Received 27 April 1977; accepted 29 June 1977)
}

\begin{abstract}
The delayed light emission decay rate (up to $120 \mu \mathrm{s}$ ) and the rise in chlorophyll $a$ fluorescence yield (from 3 to $35 \mu \mathrm{s}$ ) in isolated chloroplasts from several species, following a saturating $10 \mathrm{~ns}$ flash, are temperature independent in the $0-35^{\circ} \mathrm{C}$ range. However, delayed light in the $120-340 \mu$ sange is temperature dependent. Arrhenius plots of the exponential decay constants are: (a) linear for lettuce and pea chloroplasts but discontinuous for bush bean $\left(12-17^{\circ} \mathrm{C}\right)$ and spinach $\left(12-20^{\circ} \mathrm{C}\right)$ chloroplasts; (b) unaffected by 3-(3,4 dichlorophenyl)-1,1-dimethylurea (inhibitor of electron flow), gramicidin D (which eliminates light-induced membrane potential) and glutaraldehyde fixation (which stops gross structural changes).

The discontinuities, noted above for bush bean and spinach chloroplasts, are correlated with abrupt changes in (a) the thylakoid membrane lipid fluidity (monitored by EPR spectra of 12 nixtroxide stearate, 12 NS) and (b) the fluidity of extracted lipids (monitored by differential calorimetry and EPR spectra of $12 \mathrm{NS}$ ). However, no such discontinuity was observed in (a) chlorophyll a fluorescence intensity of thylakoids and (b) fluorescence of tryptophan residues of delipidated chloroplasts.

Microsecond delayed light is linearly dependent on light intensity at flash intensities as low as one quantum per $2 \times 10^{4}$ chlorophyll molecules. We suggest that this delayed light could originate from a one quantum process in agreement with the hypothesis that recombination of primary charges leads to this light emission. A working hypothesis for the energy levels of Photosystem II components is proposed involving a charge stabilization step on the primary acceptor side, which is in a lipid environment.

Finally, the redox potential of P680 (the reaction center for chlorophyll of system II) is calculated to be close to $1.0-1.3 \mathrm{~V}$.
\end{abstract}

\section{INTRODUCTION}

The sensitivity of delayed light emission (microsecond to second range) to temperature has been demonstrated by several methods. Light emission can be obtained from preilluminated samples by slow heating [the glow curve technique (Arnold and Sherwood, 1957; Arnold and Azzi, 1968) with four or more bursts of emission at different temperatures (Shuvalov and Litvin, 1969; Arnold and Azzi, 1971; Desai et al, 1975; Sane et al., 1977)]. Rapid heating (temperature-jump) also causes preilluminated chloroplasts to emit a pulse of delayed light (Mar and Govindjee, 1971; Jursinic and Govindjee, 1972; Malkin and Hardt, 1973). The amplitude and decay kinetics of delayed light emission are temperature dependent in the time range of seconds (Strehler and Arnold, 1951; Tollin et al., 1958; Tollin and Calvin, 1957; Sweetser et al., 1961; Jursinic and Govindjee, 1972; Laine-Böszörmenyl et al., 1972), milliseconds (Tollin et al., 1958; Swcetser et al., 1961; Lavorel, 1969) and microseconds (Zankel, 1971).

An Arrhenius plot of the delayed light emission decay rate constant for Chlorella in the $0-45^{\circ} \mathrm{C}$ range had a discontinuity between 10 and $20^{\circ} \mathrm{C}$, consisting of a segment of almost zero slope (Jursinic and Gov-

* Present address: Northern Regional Research Center, U.S. Dept. of Agriculture, 1815 N. University St., Peoria, IL 61603 .

** Reprint requests to be sent to. indjee, 1972). Up to this time a nonlinear Arrhenius plot for delayed light emission decay has not been reported for any other material. Other processes in plants vary in a discontinuous manner with temperature and in many cases this is correlated with changes in membrane lipid fluidity (Raison, 1973). Succinate oxidation activity in chill-insensitive plants (potato tubers, cauliflower buds and beet root) vary in a monotonic fashion, while in chill-sensitive plants (tomato fruit, sweet potato and cubumber fruit) in a discontinuous manner with temperature (Lyons and Raison, 1970; Raison et al., 1971). Measurements on EPR of fatty acid probes, incorporated in membranes, indicated discontinuous membrane lipid fluidity changes in the chill-sensitive but not in the chillinsensitive plants. Arrhenius plots of nicotinamide adenine dinucleotide phosphate photoreduction were linear for chill-insensitive plants (tomato and bean) (Shneyour et al., 1973). The effect of temperature on the electron transport reaction and on EPR spin labels in the blue-green alga Anacystis showed discontinuities in both the parameters at the same temperature (Murata et al., 1975). Hydrogen ion movement across the thylakoid membrane of spinach is also temperature sensitive (Gräber and Witt, 1974; Yamamoto and Nishimura, 1976), having a discontinuity at $18^{\circ} \mathrm{C}$, which is the same temperature at which EPR probes (Torres-Pereira et al., 1974) indicated a membrane phase change. 
We report here the temperature characteristics of delayed light emission decay, after a single 10 ns laser pulse, in the 6-340 $\mu$ s range for chloroplasts from both chill-sensitive (bush beans) and chill-insensitive (pea, lettuce and spinach) plants. Also, the temperature dependence of thylakoid membrane lipid fluidity as determined by EPR spectra of fatty acid spin labels and differential scanning calorimetry (DSC) are presented. Supporting data on delipidated membranes and extracted lipids are also included. We show here that a chill-sensitive plant (bush beans) and a chillinsensitive plant (spinach) behave the same way.

The current theory for the origin of delayed light emission is the recombination of $\mathrm{P}_{680}^{+}$and $\mathrm{Q}^{-}$, where $\mathrm{P}_{680}^{+}$is the oxidized form of the reaction center chlorophyll $a$ and $\mathrm{Q}^{-}$is the reduced form of the primary acceptor (Lavorel, 1975). This theory predicts a linear dependence of delayed light emission on light intensity (I). Jones (1967), Stacy et al. (1971) and Lavorel (1971) reported $I^{2}$ dependence for millisecond delayed light emission in samples given low intensity illumination of pulse lengths $1.7 \mathrm{~ms}, 3.5 \mathrm{~ms}$, and $0.28 \mathrm{~ms}$, respectively. Zankel (1971) observed a linear dependence on intensity of microsecond delayed light emission following a microsecond flash. We show in this paper that microsecond delayed light following a $10 \mathrm{~ns}$ flash is linearly dependent on light intensity at intensities an order of magnitude lower than used by Zankel (1971). This could be taken to support the primary charge recombination hypothesis for delayed light.

\section{MATERIALS AND METHODS}

Alaska peas (Pisum sativum, var. Alaska) and bush beans (Phaseolus mulgaris) were grown in vermiculite in $1 / 4$ strength Hogland's solution in a regime of $8 \mathrm{hr}$ (dark, $18^{\circ} \mathrm{C}$ ) and $16 \mathrm{~h}$ (light, $20^{\circ} \mathrm{C}$ ) cycle for 10 days. Leaves from spinach (Spinacea oleracea) and lettuce (Lactuca sativa, var. Romaine) were obtained from the local market. About $75 \mathrm{~g}$ of leaves were rinsed in ice water and then homogenized for $20 \mathrm{~s}$ in a Waring blender in $150 \mathrm{~m} /$ of buffer medium containing $0.4 M$ sucrose, $0.1 M \mathrm{~N}$-tris (hydroxylmethyl)methyl-glycine (Tricine), $5 \mathrm{mM} \mathrm{MgCl}, 10 \mathrm{mM} \mathrm{NaCl}$, and $20 \mathrm{mM}$ ascorbate adjusted to a $\mathrm{pH}$ of 7.8 . For bush bean chloroplasts, $250 \mathrm{mg}$ bovine serum albumin was also added to the grinding medium. The homogenate was strained through eight layers of cheesecloth and one layer of $10 \mu \mathrm{m}$ mesh nylon. The filtrate was centrifuged at $5000 \times g$ for $5 \mathrm{~min}$ to pellet the chloroplasts which were resuspended in a $50 \mathrm{~m} M$ sodium phosphate buffer ( $\mathrm{pH} \mathrm{7.8)} \mathrm{to} \mathrm{obtain}$ broken chloroplasts. These chloroplast fragments (thylakoids) were pelleted by another $5000 \times \mathrm{g}, 5 \mathrm{~min}$ centrifugation and were finally resuspended to a chlorophyll concentration of $3 \mathrm{mg} / \mathrm{m} /$ in the grinding medium with $50 \mathrm{mM}$ phosphate substituting Tricine. All delayed light emission and fluorescence yield measurements were made with samples containing $5 \mu \mathrm{g}$ chlorophyll/m/. Chlorophyll determination was made by the method of Arnon (1949) using MacKinney's equations (1941).

Blue-green alga Anacystis nidulans was grown at $22^{\circ} \mathrm{C}$ in Kratz and Myers' medium C (1955) using previously described procedures (Govindjee and Rabinowitch, 1960).

Extraction of lipids was carried out using the modified Bleigh-Dyer method (see Ames, 1968). Lipid-water dispersions were made by a procedure similar to that of Bangham et al. (1967) which produces multilamellar liposomes.
Microsecond and millisecond delayed light emission decays, after a single $10 \mathrm{~ns}$ flash from a nitrogen laser, were measured using apparatus described by Jursinic and Govindjee (1977) and Jursinic (1977). Chlorophyll a fluorescence measurements were made by replacing the nitrogen laser with light from an incandescent lamp, passed through a water filter and a Corning CS 4-96 glass filter. Sample temperature was regulated for both measurements by using a quartz water-jacketed fluorimeter cuvette (Precision Cell model 54FL).

EPR spectra of the fatty acid spin label 12 nitroxide stearate (obtained from Syva, Palo Alto, California; incorporated into chloroplast membranes or lipid-water dispersions) were measured in a Varian (Model E-9) EPR spectrometer with a Varian (Model V-4540) variable temperature controller. Samples were held in glass tubes $9.3 \mathrm{~cm}$ long having a $2 \mathrm{~mm}$ inside diameter, and the temperature was measured inside the tube with a thermistor (Fenwal Electronics, Type GB32J2). Spectra were recorded within 60-90 min after introduction of the spin label to obtain the largest signals. By $120 \mathrm{~min}$ after addition of the spin label, the signal amplitude had decreased by one-half due to chemical reduction of the paramagnetic nitroxide group by membrane components (see Gaffney, 1975). For all EPR data, spectra were taken at a particular temperature after the sample had been at that temperature for $5 \mathrm{~min}$. To check the EPR method, $12 \mathrm{NS}$ was incorporated into a lipid-water dispersion of 1-2-dipalmitoyl-L-lecithin (lecithin/water, 34/66, w/w) and a characteristic sharp phase transition was observed at $41^{\circ} \mathrm{C}$, as expected (Barratt et al., 1969).

Incorporation of nitroxide stearate (12 NS) into chloroplast membranes or lipid-water dispersions was made as follows: (1) $12 \mathrm{NS}$ in ethanol was added to a small test tube, and the ethanol was blown off with nitrogen, (2) chloroplasts at a chlorophyll concentration of $15 \mathrm{mg} / \mathrm{m} /$ or lipid and water were added to give a final molar ratio of chlorophyll to 12 NS of 15 to 1 , and (3) thorough mixing was accomplished by using a vortex mixer for $5 \mathrm{~min}$ at $50^{\circ} \mathrm{C}$.

For differential scanning calorimetry, a Perkin--Elmer DSC-2 calorimeter with a refrigeration unit was used. The tcmperature and enthalpy scales were calibrated with known masses of pure indium and lead. Samples were placed in hermetically sealed $20 \mu$ aluminum pans and the reference pan contained phosphate buffer. To check the calorimeter, scans were made on a lipid-water dispersion of 1, 2-dipalmitoyl-L-lecithin (lecithin/water, 34/66, $w / w)$ and a characteristic sharp peak was observed at $41^{\circ} \mathrm{C}$ and a small pretransition at $34^{\circ} \mathrm{C}$, as expected (Chapman et al., 1974).

The fluorescence of tryptophan was measured on a Perkin-Elmer spectrofluorometer (model MPF-3) fitted with a temperature regulation unit. These measurements were carried out on chloroplasts delipidated according to procedures described by Hess and Benson (1968) and Isaakidou and Papageorgiou (1975).

Glutaraldehyde fixed spinach chloroplasts were prepared according to Zilinskas and Govindjee (1976). Absorption measurements to determine the extent of glutaraldehyde fixation were made with a Cary-14 spectrophotometer. The rates of $\mathrm{O}_{2}$ evolution, with ferricyanide as an electron acceptor, were determined under saturating continuous illumination with a Yellow Springs Instrument platinum/ $\mathrm{Ag}-\mathrm{AgCl}_{2} \mathrm{Clark}$ electrode and Model 53 oxygen monitoring system.

\section{RESULTS}

\section{Microsecond delayed light emission dependence on light} intensity

Single $1 \mathrm{~mJ}$ pulses of $337 \mathrm{~nm}$ laser light were capable of just saturating microsecond delayed light 

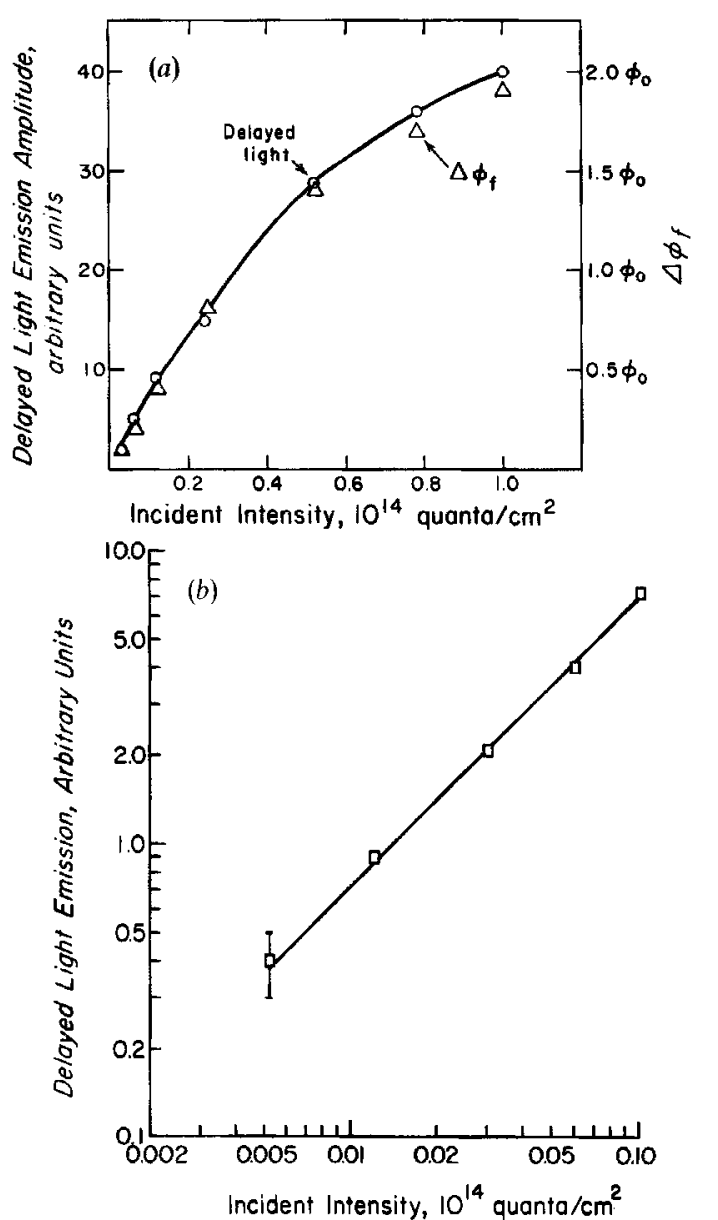

Figure 1. Delayed light emission in Alaska pea chloroplasts as a function of light intensity; intensities were varied by neutral density filters calibrated at $337 \mathrm{~nm}$; chlorophyll concentration, $5 \mu \mathrm{g} / \mathrm{m} /$ suspension. (a): Delayed light emission at $100 \mu \mathrm{s}$ after a $10 \mathrm{~ns}$ excitation flash; also shown is the variable chlorophyll $a$ fluorescence yield $\left(\Delta \phi_{f}\right)$ at $20 \mu$ s after the excitation flash in units of $\phi_{0}$, the level of chlorophyll a fluorescence yield prior to excitation. Dark adaptation, $5 \mathrm{~min}$; the maximum incident laser intensity, $10^{14}$ quanta/ $\mathrm{cm}^{2} \equiv$ to an absorption of 1 quantum per $\sim 100$ chlorophyll molecules. (b): A logarithmic plot of the intensity of delayed light emission at $60 \mu \mathrm{s}$ after a $10 \mathrm{~ns}$ excitation flash vs the logarithm of the incident flash intensity. A single excitation flash was given after a dark adaptation period of $15 \mathrm{~min}$. The lowest incident laser light intensity shown $\left(5 \times 10^{11}\right.$ quanta $\left./ \mathrm{cm}^{2}\right)$ is equivalent to 1 quantum absorbed per $2 \times 10^{4}$ chlorophyll molecules. The maximum possible error is shown by a verticalbar. Note the slope of the curve is 1.0 (average of three separate experiments), not 2.0 .

* $P=P_{0}\left(1-\mathrm{e}^{-I \sigma}\right)$, where $P_{0}$ is the greatest value of the measured phenomenon (in our case, delayed light emission), $I=$ intensity of incident quanta, and $\sigma=$ absorption cross section. Mauzerall (1976) has observed that $\phi_{f}$ rise follows the Poisson law quite well at low light intensities. When $I \sigma=1, P=P_{0}(1-1 / \mathrm{e})$ or $P \approx 0.67 P_{0}$; from the intensity at which this happens, we can calculate $\sigma$ as $1 / 1$ (in $\mathrm{cm}^{2}$ ). From the chlorophyll concentration $/ \mathrm{cm}^{2}$, we then obtain the number of chlorophyll molecules $/ \mathrm{cm}^{2}$, and from the knowledge of the cross section of a single chlorophyll molecule, we can obtain the number of chlorophyll molecules per photosynthetic unit (see Weaver and Weaver, 1969). emission and chlorophyll a fluorescence yield in chloroplast samples containing a $5 \mu \mathrm{g}$ chlorophyll $/ \mathrm{m} /$ suspension (Fig. 1a). Saturation (1 quantum absorbed per photosynthetic unit) occurred at a calculated* intensity level of 1 quantum per approximately 200 chlorophyll molecules. The laser intensity was kept at twice this level in all experiments except those done to check intensity dependence. The laser pulse intensity, measured with a JEN-TEC Model ED500) joule meter, was just saturating at an incident intensity of $5 \times 10^{13}$ quanta $/ \mathrm{cm}^{2}$ equivalent to $1.8 \times 10^{13}$ absorbed quanta $/ \mathrm{cm}^{2}$ since the percent absorption was $36 \%$ at $337 \mathrm{~nm}$ (measured by suspending chloroplasts in $7 \%$ Ficoll).

To test whether delayed light emission intensity follows $I$ or $I^{2}$ dependence (information necessary to understand the mechanism for its generation), light curves were made at very low light intensities (where multiple hits of the reaction center do not occur). Alaska pea chloroplasts were kept in complete darkness for $15 \mathrm{~min}$ [as was done by Jones (1967)] to allow for the decay of any energy trapping states. A $\log -\log$ plot (Fig. 1b) of $\mu$ s delayed light intensity shows a slope of unity, indicating that a one quantum process is involved. This finding is in agreement with results at an order of magnitude higher intensity of $\mu$ s flash illumination (Zankel, 1971), but does not agree with a slope of 2 found for ms flash illumination (Jones, 1967; Stacy et al., 1971; Lavorel, 1971).

Temperature dependence of delayed light emission decay and chlorophyll a fluorescence yield

The decay of delayed light emission in the $6-340 \mu \mathrm{s}$ range in Alaska pea chloroplasts at 3 or $25^{\circ} \mathrm{C}$ is shown in Fig. 2(a) and (b). $0.1 \mu M$ 3-(3,4 dichlorophenyl)-1,1-dimethylurea (1:50 chlorophyll) was present in these samples to avoid complication due to temperature induced changes in the electron flow from $\mathrm{Q}^{-}$to the intersystem pool. The rapidly decaying components at $t<100 \mu$ s show no change in kinetics with temperature, but the delayed light emission intensity increases with increasing temperature. The fast component is temperature insensitive within experimental errors. The enhancement of intensity is due to increase in the amplitude of the slow decaying component. A temperature effect on the decay kinetics is observed beyond $120 \mu \mathrm{s}$ after the flash, with the lifetimes being $58 \mu \mathrm{s}$ at $25^{\circ} \mathrm{C}$ and $100 \mu \mathrm{s}$ at $3^{\circ} \mathrm{C}$. This agrees with temperature effects on delayed light emission decay kinetics in the 65 to $250 \mu$ s time range in spinach chloroplasts (Zankel, 1971). Chloroplasts without DCMU had the same temperature effects as seen in Fig. 2 (not shown).

The rise in chlorophyll $a$ fluorescence yield, after an excitation flash, for chloroplasts at $3^{\circ} \mathrm{C}$ is the same as at $25^{\circ} \mathrm{C}$ (Fig. 3 ).

Arrhenius plots of the exponential decay constant $k$ for $120-340 \mu$ s delayed light showed a linear curve for lettuce but a discontinuity between 12 and $17^{\circ} \mathrm{C}$ for bush bean chloroplasts (Fig. 4). 

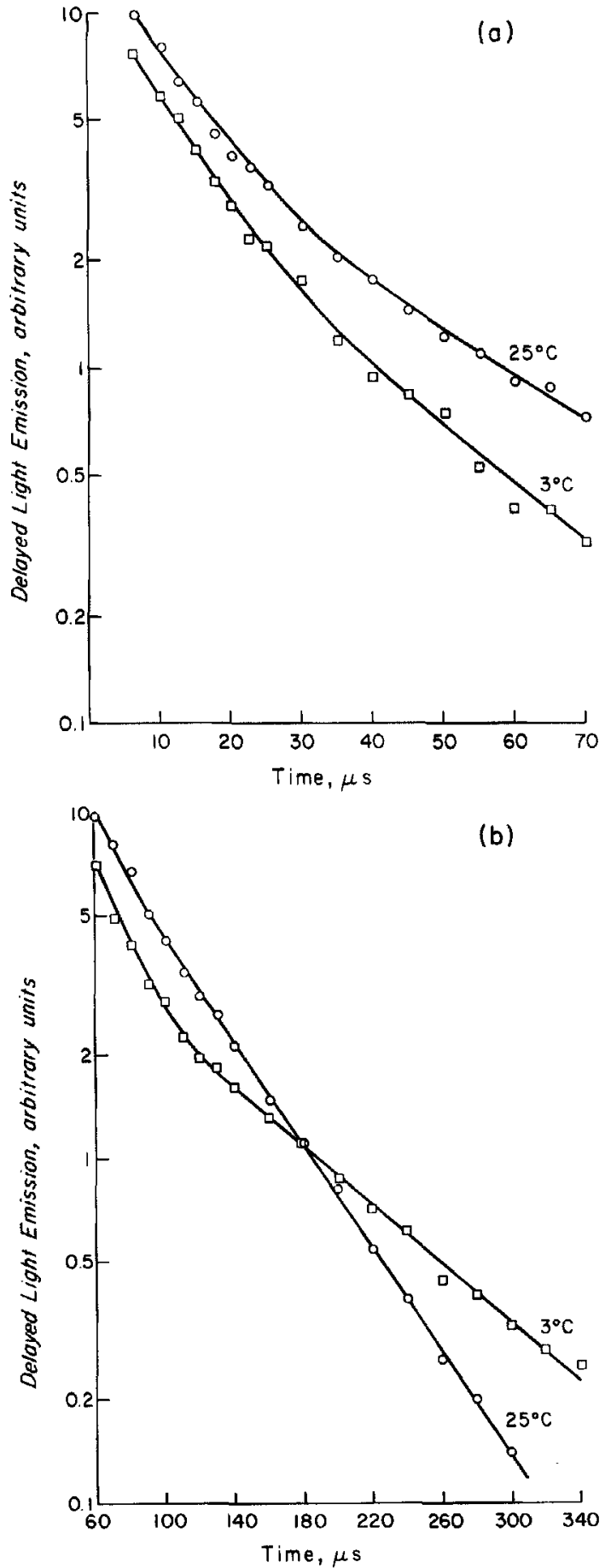

Figure 2. Logarithmic plot of the delayed light emission decay in the $6-340 \mu \mathrm{s}$ range at 3 and $25^{\circ} \mathrm{C}$ after a final flash in a series of eight or more flashes given at a rate of 1 flash $/ 2 \mathrm{~s}$. Alaska pea chloroplasts with $0.1 \mu \mathrm{M} \mathrm{DCMU}$; chlorophyll concentration, $5 \mu \mathrm{g} / \mathrm{m} \ell$. (a): 6-70 $\mu$ s range; (b): 60-340 $\mu$ s range.

Upon illumination, a membrane potential, $\Psi_{l}$, of $50-135 \mathrm{mV}$ is established across the thylakoid membrane (Junge and Witt, 1968; Zickler and Witt, 1976; Jursinic et al., 1977). It was suggested by Fleischman (1971) that the activation energy for delayed light emission, $\boldsymbol{E}_{a}$, will be decreased by $\Psi_{1}$ as follows:

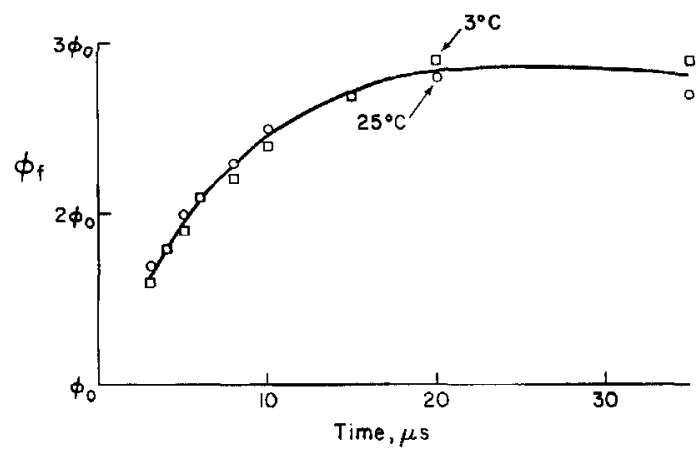

Figure 3. Rise in chlorophyll $a$ fluorescence yield, $\phi_{f}$, in the 3-35 $\mu$ s range at 3 and $25^{\circ} \mathrm{C}$, following a final flash in a series of eight or more flashes given at a rate of 1 flash $/ 2 \mathrm{~s} . \phi_{0}$, the level of fluorescence prior to an actinic flash; Alaska pea chloroplasts; chlorophyll concentration, $5 \mu \mathrm{g} / \mathrm{m} \ell ; 25^{\circ} \mathrm{C}(0-0-0)$ and $3^{\circ} \mathrm{C}(\square-\square-\square)$.

$E_{a}^{\prime}=\left(E_{a}-\Psi_{\vartheta}\right)$. We looked for this effect in our Arrhenius plots in samples that have $\Psi_{l}$ eliminated (as tested by the absence of $515 \mathrm{~nm}$ electrochromic shift) in the $\mu$ s range by gramicidin D [Fig. 5(a) and (b)], but found that the activation energies differ by only $15 \mathrm{meV}$, not $100 \mathrm{meV}$, the approximate value of $\Psi_{I}$ in this time range (Jursinic et al., 1977).

We then tested to see if discontinuities seen in Arrhenius plots might be due to large structural changes in the thylakoid membrane. Glutaraldehyde fixation

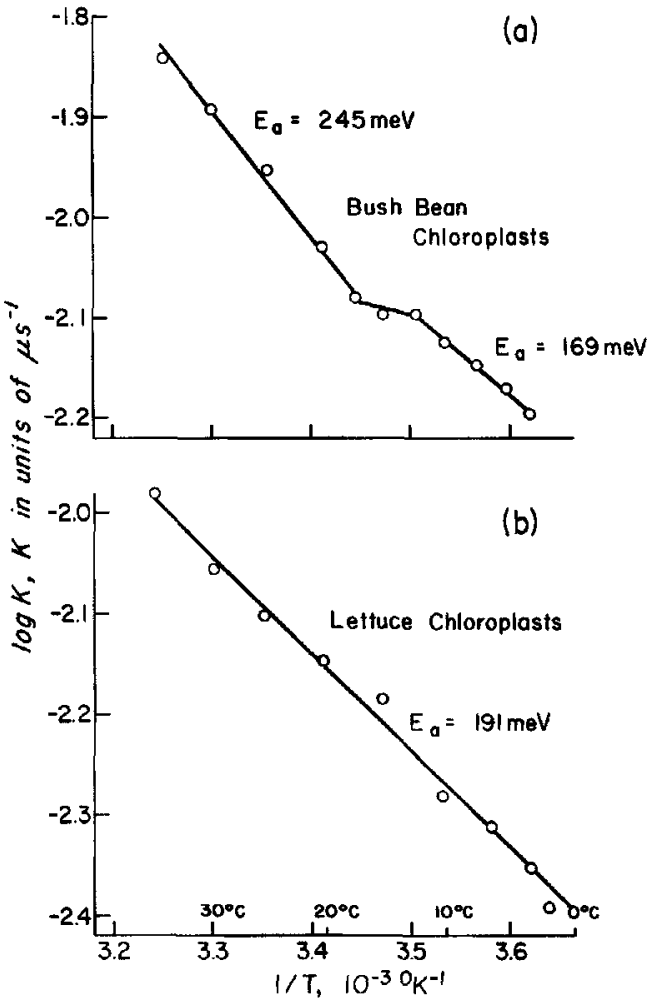

Figure 4. Arrhenius plots of the exponential decay constant, $k$, obtained from semilogarithmic plots of delayed light emission decay in the $120-340 \mu$ s range from (a) bush bean chloroplasts and (b) lettuce chloroplasts with $0.1 \mu M$ DCMU present. Chlorophyll concentration, $5 \mu \mathrm{g} / \mathrm{m} \ell$. The calculated activation energies, $E_{a}$, are given on the figure in millielectron volts $(\mathrm{meV})$ 


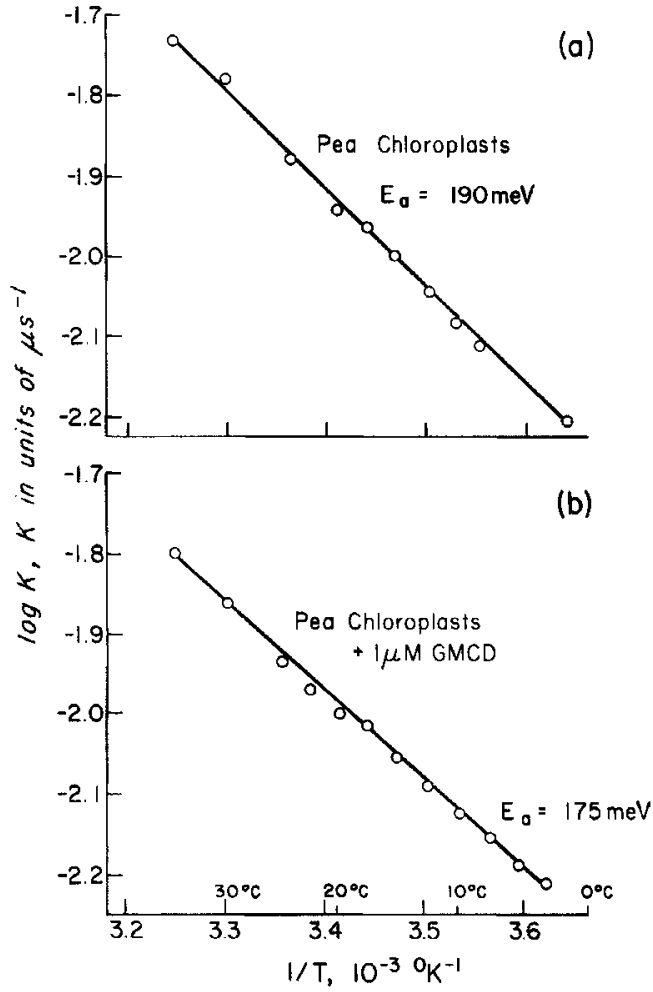

Figure 5. Arrhenius plots of the exponential decay constant, $k$, obtained from semilogarithmic plots of delayed light emission decay in the $120-340 \mu$ s range from (a) Alaska pea chloroplasts, control and (b) with $1 \mu M$ gramicidin D. Chlorophyll concentration, $5 \mu \mathrm{g} / \mathrm{m} /$. The calculated activation energy, $E_{a}$, are given on the graph in millielectron volts (meV).

of chloroplasts was used to block large structural changes (Murakami and Packer, 1970). Glutaraldehyde fixed chloroplasts, used in our experiments, were completely fixed according to previously established criteria (Zilinskas and Govindjee, 1976) and retained $30 \%$ of their capacity to evolve oxygen. Arrhenius plots of the delayed light emission decay constant in both fixed and unfixed spinach chloroplasts showed discontinuities (Fig. 6).

Fatty acid spin labelling of thylakoid membrane and water dispersions of lipids

Paramagnetic spin labels, when incorporated into biological membranes, provide information about the fluidity of their environment (Gaffney, 1974). Various spin labels have been used to detect membrane lipid phase transitions in microorganisms (Tourtellotte et al., 1970; Sackmann et al., 1973; Hsung et al., 1974), animal cells (Lyons and Raison, 1970; Wisnieski et al., 1971; McMurchie et al., 1973; Raison and McMurchie, 1974) and plant cells (Shneyour et al., 1973; Murata et al., 1975). We used $12 \mathrm{NS}$ to determine if the thylakoid membrane lipids in our samples undergo phase transitions that could be correlated with the delayed light emission Arrhenius plot discontinuities.
The hyperfine splitting constant $\left(2 \mathrm{~T}_{11}\right)$ in EPR spectra can be taken as an indicator of the mobility of the spin label in membrane lipids (Sackman et al., 1973). Figure 7 is a plot of $2 T_{11}$ versus temperature for $12 \mathrm{NS}$ in bush bean chloroplast membranes and in a water dispersion of extracted lipids from the same chloroplasts. A change in the slope occurs between $13 \pm 1^{\circ} \mathrm{C}$ for both preparations and is interpreted as a change in the membrane lipid fluidity.

For membranes with a low viscosity, the hyperfine splitting peaks in EPR spectra are not resolved; instead, the rotational correlation time, $\tau_{c}$, may be calculated from line broadening in the spectra (Shneyour et al., 1973). The low viscosity condition existed for 12 NS incorporated into Alaska pea chloroplast membranes and water dispersions of extracted lipids from the same chloroplasts. A plot of the rotational correlation time versus the reciprocal of temperature was linear (Fig. 8) and is interpreted to indicate that no discontinuous change in membrane lipid fluidity occurs in Alaska pea chloroplasts in this temperature range.

Differential scanning calorimetry of water dispersions of extracted lipids

Differential scanning calorimetry was used as an independent method to measure lipid phase transi-

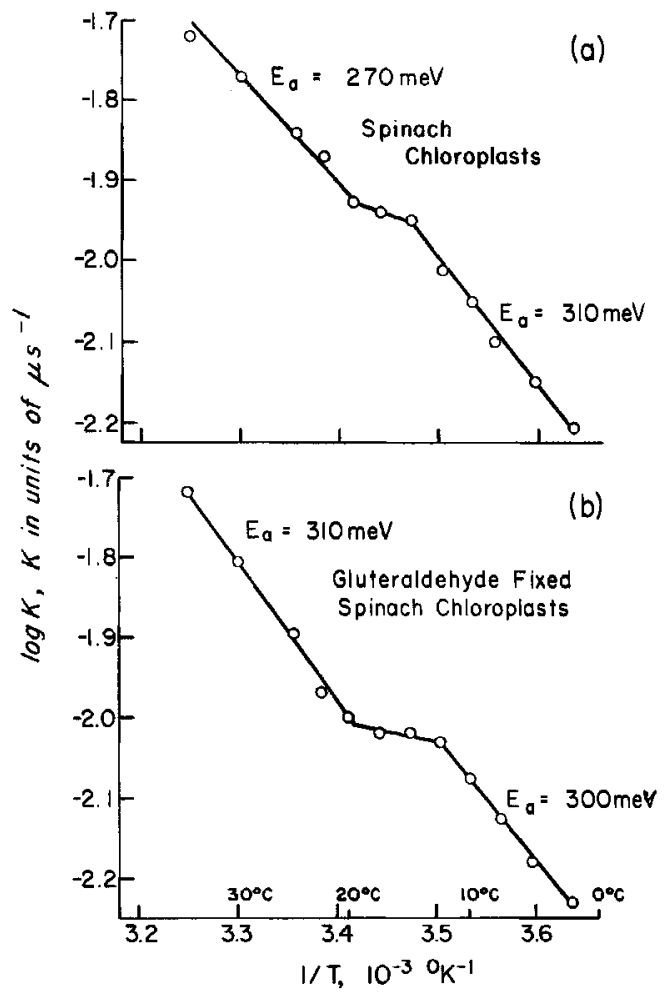

Figure 6. Arrhenius plots of the exponential decay constant, $k$, obtained from semilogarithmic plots of delayed light emission decay in the $120-340 \mu$ s range from (a) unfixed and (b) glutaraldehyde fixed spinach chloroplasts, with $0.1 \mu M$ DCMU present. Chlorophyll concentration, $5 \mu \mathrm{g} / \mathrm{m} \ell$. The activation energy, $E_{a}$, calculated from the Arrhenius plot slope is given on the figure in millielectron volts (meV). 


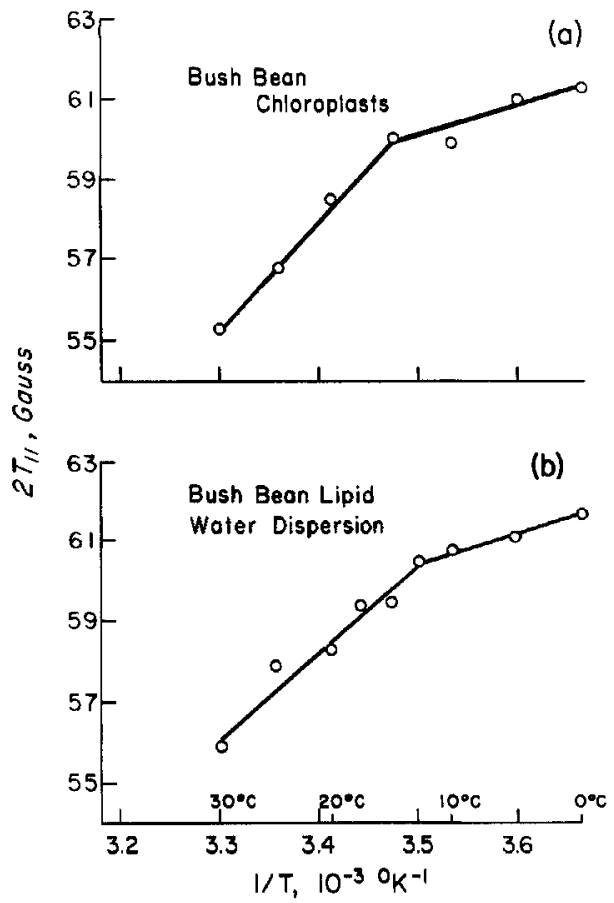

Figure 7. The maximum hyperfine splitting of EPR spectrum, $2 \mathrm{~T}_{y}$, of $12 \mathrm{NS}$ vs the reciprocal of absolute temperature from bush bean chloroplasts and a water dispersion of extracted bush bean lipids. The 12NS was at a toncentration of one per 15 chlorophyll in (a) bush bean chloroplasts and (b) a lipid-water dispersion ( $20 \mathrm{mg}$ chlorophyll; $300 \mathrm{mg}$ water) of lipids extracted from bush bean chloroplasts. The EPR spectrometer settings were: scan time, $4 \mathrm{~min}$; time constant, $1 \mathrm{~s}$; microwave power, $20 \mathrm{~mW}$; and modulation amplitude, $1 \mathrm{G}$.

tions. This technique has been used in lipid water dispersions, membrane fragments and whole cells (Steim et al., 1969; Reinert and Steim, 1970; Ashe and Steim, 1971; Blazyk and Steim, 1972; Chapman et al., 1974). Due to the low lipid mass of bush bean and Alaska pea chloroplasts, we were unable to observe transition peaks in whole membranes. (Earlier reports of transition peaks in whole membranes were only made possible by the use of specially prepared sample pans having a seven-fold greater volume than those available for our use.) However, by extracting chloroplast lipids and making water dispersions, approximately five times as much lipid mass could be placed in the sample pan than was possible with whole chloroplast membranes. Figure 9 shows calorimetry scans for a water dispersion of lipids extracted from bush bean chloroplasts. Increasing and decreasing temperature scans are shown with the latter having the broadest transition $\left(10^{\circ} \mathrm{C}\right)$; both transition peaks occur at about $15^{\circ} \mathrm{C}$. Water dispersions of extracted lipids of Alaska pea chloroplasts did not show transition peaks.

\section{Chlorophyll a fluorescence as a function of temperature}

EPR fatty acid spin labels have been used to demonstrate that membrane lipids of the blue-green alga Anacystis nidulans undergo a phase transition at

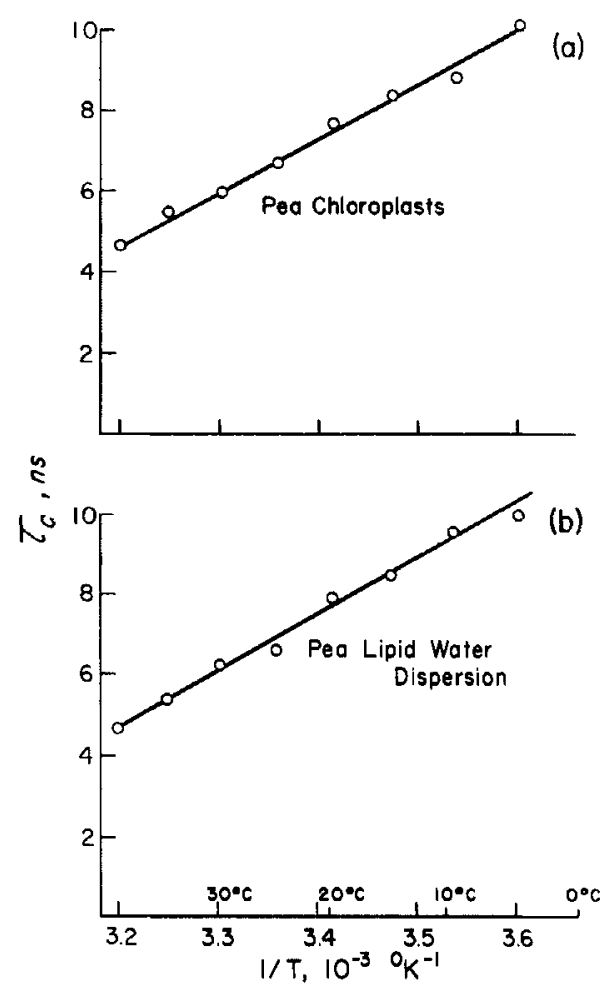

Figure 8. The rotational correlation time, $\tau_{\circ}$ of $12 \mathrm{NS}$ versus the reciprocal of absolute temperature in Alaska pea chloroplasts and a water dispersion of extracted Alaska pea lipids. The 12NS was at a concentration of one per 15 chlorophyll in (a) Alaska pea chloroplasts and (b) a lipid-water dispersion (20 mg chlorophyll: $300 \mathrm{mg}$ water) of lipids extracted from Alaska pea chloroplasts. For other details, see the legend of Fig. 7.

approximately 13 or $24^{\circ} \mathrm{C}$ in organisms grown at 28 or $38^{\circ} \mathrm{C}$ respectively (Murata et al., 1975). The chlorophyll a fluorescence from intact cells of Anacystis with DCMU present had a temperature dependence with

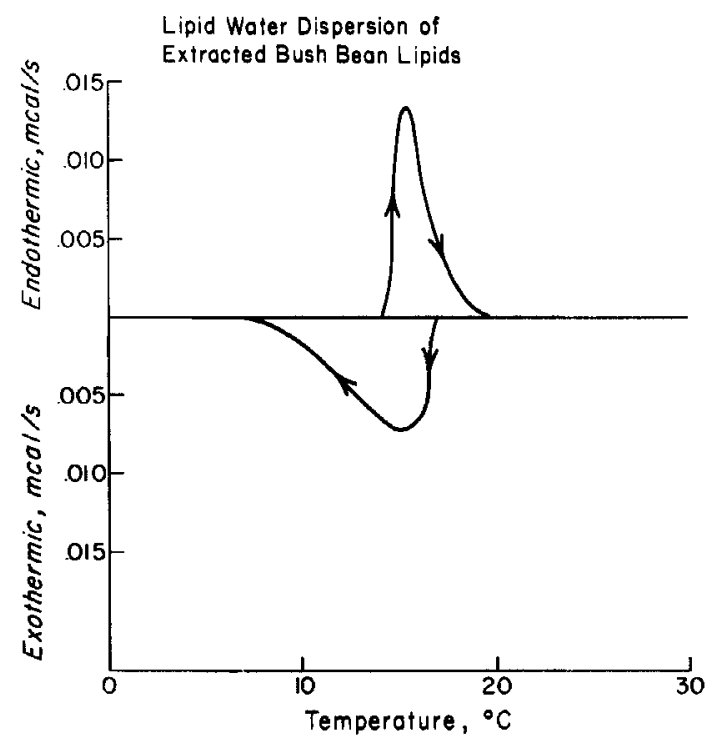

Figure 9. Differential scanning calorimeter scans of a water dispersion of lipids extracted from bush bean chloroplasts (lipid/water, 1/2.6, w/w). Samples, $3.6 \mathrm{mg}$ total lipid; scanning rate, $5^{\circ} \mathrm{C} / \mathrm{min}$. 


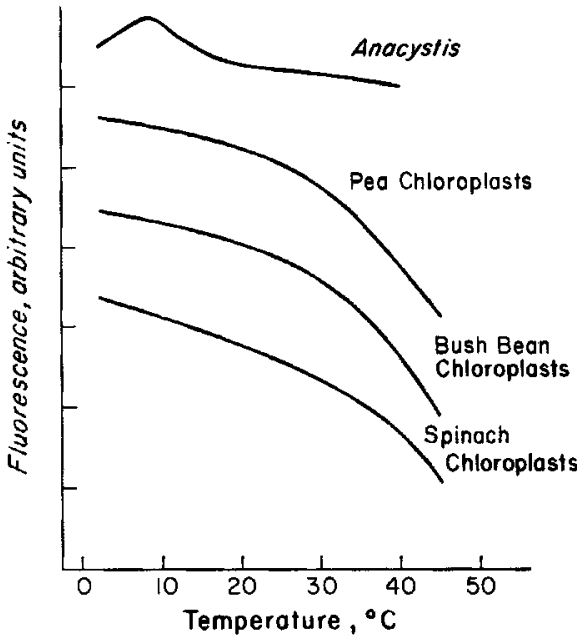

Figure 10. Temperature dependence of chlorophyll $a$ fluorescence intensity in Anacystis nidulans grown at $22^{\circ} \mathrm{C}$ and chloroplasts of Alaska pea, bush bean and spinach. All samples had $1 \mu M$ DCMU present. Chlorophyll concentrations: $1 \mu \mathrm{g} / \mathrm{ml}$ (Anacystis) or $5 \mu \mathrm{g} / \mathrm{ml}$ (chloroplasts). Fluorescence was excited by light from an incadescent lamp passed through a water filter and a Corning CS4-96 glass filter and measured through a $686 \mathrm{~nm}$ interference filter. The intensity of the exciting light was $15 \mathrm{~W} / \mathrm{m}^{2}$ incident at the sample.

a peak at the transition temperature (Murata et al., 1975; Murata and Fork, 1975). Measurements were made of chlorophyll a fluorescence in chloroplasts of Alaska pea, bush bean and spinach to see if any correlation might occur between the fluorescence temperature dependence and the delayed light emission, EPR and scanning calorimetry data. The chlorophyll $a$ fluorescence temperature dependence of Anacystis grown at $22^{\circ} \mathrm{C}$ is observed to be maximal at $9^{\circ} \mathrm{C}$ (Fig. 10 ), which agrees with the result of Murata and Fork (1975). However, no peak in the fluorescence temperature dependence is observed for Alaska pea, bush bean or spinach chloroplasts (Fig. 10). Note that bush bean and spinach chloroplasts showed discontinuities in delayed light emission decay rates, but Alaska pea chloroplasts did not. It seems that chlorophyll $a$ fluorescence changes cannot be taken as a reliable indicator of membrane fluidity changes because bush bean chloroplasts and their lipids showed a negative correlation between fluorescence changes and the fluidity measured by EPR and calorimetry methods.

\section{Tryptophyl fluorescence as a function of temperature}

The EPR and scanning calorimetry data provide information about the temperature effects on lipids especially when lipid-water dispersions are involved. To determine if membrane proteins might show discontinuous temperature behavior, the protein fluorescence of delipidated chloroplasts was measured at various temperatures. The fluorescence peaked at $330 \mathrm{~nm}$ (uncorrected spectra) when $280 \mathrm{~nm}$ excitation was used. This is the fluorescence peak from chloroplast protein tryptophyl residues (Isaakidou and Papageorgiou, 1975); it showed a linearly decreasing intensity with increasing temperature (Fig. 11) for both bush bean and Alaska pea delipidated chloroplasts.

\section{DISCUSSION}

Is microsecond delayed light emission a one quantum process?

The dependence of microsecond delayed light emission at low light intensities on the first power of the light intensity (I) (Fig. 1) confirms the observation of Lavorel (1975) that $I^{2}$ dependence becomes an $I$ dependence when the illumination time drops below $100 \mu$ s. The $I$ dependence at extremely low light intensities could indicate that microsecond delayed light emission is a one quantum process. This would suggest that theories requiring two quanta, such as electron-hole recombination (Arnold and Azzi, 1968; Bertsch, 1969; Arnold, 1976) and the triplet-triplet fusion (Stacy et al., 1971), may not be valid for explaining light emitted in the $\mu$ s time range. The $I$ dependence is consistent with the charge recombination theory of delayed light emission, since only one photon need be absorbed to generate the charge couple that can recombine to give delayed light emission. Arnold (personal communication) has, however, pointed out that in order to deplete all electrons and holes we should have dark-adapted our chloroplasts

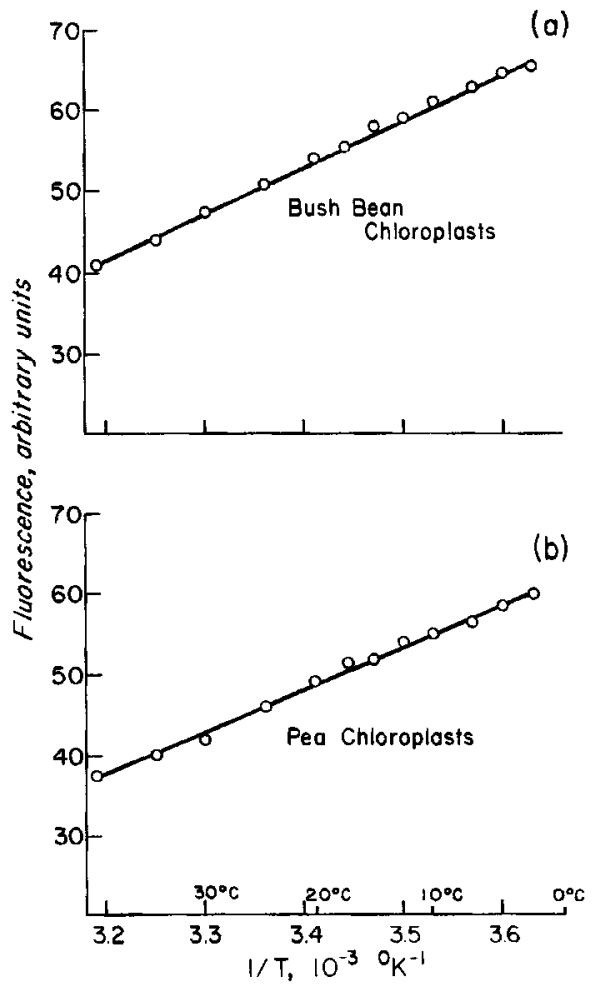

Figure 11. Temperature dependence of tryptophan fluorescence from delipidated (a) bush bean chloroplasts and (b) Alaska pea chloroplasts. Fluorescence measurements were made with a Perkin-Elmer MPF-3 spectrofluorometer with a temperature regulated cuvette. Excitation $\lambda 280 \mathrm{~nm}$; measuring $\lambda, 330 \mathrm{~nm}$. 
for $3-4 \mathrm{~h}$. However, we note that $15 \mathrm{~min}$ dark adaptation was enough for Jones (1967) and Stacy et al. (1971) to observe an $I^{2}$ dependence in $\mathrm{ms}$ flashes.

Temperature sensitivity of microsecond delayed light emission

The kinetics of delayed light emission decay at $<120 \mu \mathrm{s}$, after a $10 \mathrm{~ns}$ excitation flash, are temperature insensitive within experimental errors, while those at $>120 \mu$ s are temperature dependent (Fig. 2). The decay kinetics of delayed light emission for times less than $20 \mu \mathrm{s}$ is believed (Den Haan et al., 1974; Jursinic and Govindjee, 1977) to be due to the removal of the oxidizing equivalent from $\mathrm{P}_{680}^{+}$by the following reaction: $\mathrm{ZP}_{680}^{+} \mathrm{Q}^{-} \rightarrow \mathrm{Z}^{+} \mathrm{P}_{680} \mathrm{Q}^{-}$, where $\mathrm{P}_{680}^{+}$ is the oxidized form of the Photosystem II reaction center chlorophyll, $\mathrm{Q}^{-}$is the reduced form of the "primary" electron acceptor, and $\mathbf{Z}$ is a secondary electron donor. The rise in chlorophyll $a$ fluorescence yield following an excitation flash is also believed* to monitor the above reaction (Den Haan et al., 1974). As expected from the delayed light emission data (Fig. 2), the $\mathrm{ZP}_{680}^{+} \mathrm{Q}^{-} \rightarrow \mathrm{Z}^{+} \mathrm{P}_{680} \mathrm{Q}^{-}$reaction (assumed to be measured as fluorescence rise) had no temperature sensitivity in chloroplasts (Fig. 3). The experimental finding is in agreement with the temperature insensitivity reported for the fluorescence rise in the green alga Chlorella by Mauzerall (1972). Temperature independent electron transport reactions have been previously observed in biological systems (DeVaùlt and Chance, 1966; Fleischman, 1974) and have been interpreted to be due to electron tunneling. Our experiments were restricted to a narrow temperature range and must be extendeed to lower temperatures before any conclusion is made. An alternate possibility for explaining the temperature insensitivity is that $\mathbf{Z}$ and $\mathrm{P}_{680}$ are located in a protein complex in such a way that they are not affected by changes in the fuidity of the lipid environment.

Arrhenius plots of the rate constant $k(k=1 / \tau$, where $\tau$ is the exponential decay lifetime) for the delayed light emission component at times between 120 and $340 \mu$ s were discontinuous for bush bean and

* The interpretation of chlorophyll $a$ fluorescence yield rise is not yet fully understood. Duysens et al. (1974) observed a $1 \mu$ s rise for the first flash and a slower rising component on all the succeeding flashes. They suggested that a $10-20 \mu$ s rise may be due to the disappearance of a triplet quencher, but this needs to be proven. Mathis et al. (1976) did not observe a several- $\mu$ s component in the decay of $\mathbf{P}_{680}^{+}$to $\mathbf{P}_{680}$ and suggested that a much faster component may exist. A positive evidence of a fast ( $\leq 1 \mu \mathrm{s})$ component for the rereduction of $\mathrm{P}_{680}^{+}$, by absorption methods, needs to be presented. It is considered likely that the $6 \mu \mathrm{s}$ DLE and fluorescence component, observed by Jursinic and Govindjee (1977), is due to two phenomena: (a) reduction of $P_{680}^{+}$by $Z$; and (b) the removal of a triplet state. Parallel measurements on absorption changes due to $P_{680}^{+}$and triplets, delayed light emission and fluorescence yield changes on the same sample are necessary before firm interpretations of the various components can be made. spinach chloroplasts (Figs. 4 and 6) but linear for lettuce and Alaska pea chloroplasts (Figs. 4 and 5). This discontinuous change in the Arrhenius plot is correlated with the abrupt changes in the fluidity of the thylakoid membrane lipids. From EPR spectra of fatty acid spin labels incorporated in chloroplasts [Figs. 7(a) and 8(a)] and from differential scanning calorimetry data from water-lipid dispersion (Fig. 9), the occurrence of discontinuous changes in membrane fluidity for bush bean chloroplasts is indicated while for Alaska pea chloroplasts it is not. Table 1 presents the temperatures at which discontinuities in delayed light emission decay constants occurred and at which membrane lipid phase transitions were indicated by electron spin resonance and differential scanning calorimetry. There is a good correlation between the occurrence of discontinuities in delayed light emission decay and changes in membrane lipid fluidity. Since large structural changes cannot occur in glutaraldehyde fixed chloroplasts (Murakami and Packer, 1970) changes in membrane lipids at $18^{\circ} \mathrm{C}$, indicated by electron spin resonance fatty acid spin labels (TorresPereira et al. 1974) in fixed spinach chloroplasts, can only cause microconformational changes. The discontinuity in delayed light emission decay between 12 and $20^{\circ} \mathrm{C}$ in fixed spinach chloroplasts (Fig. 6(b)) indicates that large structural changes are not required for it, but the delayed light emission decay is sensitive to the membrane lipid fluidity changes that occur even in glutaraldehyde-fixed samples.

The Arrhenius plot of the delayed light emission decay constant was not affected by the presence or absence of DCMU. Thus, temperature effects on the electron flow between Photosystem II and I are not involved here. Also, the invariance of Arrhenius plot activation energy when the light generated membrane potential was eliminated by gramicidin D (Fig. 5) indicates that whatever reaction determines the kinetics of the temperature sensitive delayed light emission decay, its "activation energy" is unaffected by membrane potential. This agrees with the recent finding of Jursinic et al. (1977) that delayed light emission in the $\mu$ s range is insensitive to light and salt-jump generated membrane potential.

\section{Temperature sensitivity of chlorophyll a fluorescence yield}

The use of chlorophyll $a$ fluorescence as an indicator of membrane lipid phase transitions in higher plants was not successful. Both bush bean and spinach chloroplasts had discontinuous membrane lipid fluidity changes indicated by electron spin resonance data, but chlorophyll a fluorescence in these chloroplasts uniformly decreased with increasing temperature (Fig. 10). Such a negative correlation in spinach chloroplasts had been noted by Murata and Fork (1975). Also, tomato chloroplasts had no discontinuous change in chlorophyll $a$ fluorescence as a function of temperature (Murata and Fork, 1975), although tomato chloroplast lipids were shown (Rai- 
Table 1. Temperature characteristics of chloroplasts and their extracted lipids

\begin{tabular}{lccc}
\multicolumn{1}{c|}{ Sample } & $\begin{array}{c}\text { Differential } \\
\text { scanning } \\
\text { calorimetry }\end{array}$ & $\begin{array}{c}\text { Measurement } \\
\text { EPR of }\end{array}$ & $\begin{array}{c}\text { Delayed light } \\
\text { emission for }\end{array}$ \\
\hline $\begin{array}{l}\text { Alaska pea chloroplasts } \\
\text { Lipid-water dispersion of lipids extracted from Alaska pea } \\
\text { chloroplasts }\end{array}$ & - & none & none \\
$\begin{array}{l}\text { Bush bean chloroplasts } \\
\text { Lipid-water dispersion of lipids extracted from bush bean } \\
\text { chloroplasts }\end{array}$ & $120<t<340 \mu \mathrm{s}$ & 15 \\
\hline
\end{tabular}

Temperature or range of temperatures in ${ }^{\circ} \mathrm{C}$ at which a discontinuity was observed in a particular measurement.

son, 1973) to undergo a phase transition at $10^{\circ} \mathrm{C}$ using fatty acid spin labels. In the algae Anacystis, Cyanidium, and Euglena, however, peaks in the chlorophyll a fluorescence as a function of temperature were observed (Murata and Fork, 1976) and, at least for Anacystis, this peak was associated with a membrane lipid fluidity transition (Murata et al., 1975). We were also able to observe a peak in chlorophyll $a$ fluorescence at $9^{\circ} \mathrm{C}$ (Fig. 10) in Anacystis grown at $22^{\circ} \mathrm{C}$. It seems that chlorophyll $a$ fluorescence may act as an indicator of membrane lipid fluidity in algae but not in higher plant chloroplasts.

\section{Temperature sensitivity of delipidated chloroplasts}

The fluorescence of tryptophyl residues in delipidated chloroplasts of bush beans and peas uniformly decreased with increasing temperature (Fig. 11). This, along with the finding that a lipid-water dispersion of extracted bush bean lipids shows a temperature discontinuity as does delayed light emission (Table 1), indicated that membrane lipids, but not proteins, are critical in determining the temperature discontinuity in delayed light emission decay at times greater than $120 \mu \mathrm{s}$. We interpret this to mean that the delayed light emission decay at times greater than $120 \mu \mathrm{s}$ is sensitive to the environment in which Photosystem II is located and this environment is altered by the lipid fluidity of the thylakoid membrane.

Free energy changes involved in photosystem II charge separation: a working hypothesis

The arguments made here are very similar to those. made by Zankel (1971); however, we include data on the $6 \mu$ s delayed light emission decay component, which he was unable to measure. Figure 12 is a proposed energy level diagram. Upon absorption of a quantum, $h v_{\mathrm{II}}$, chlorophyll goes into an excited state which may be de-excited by emitting fluorescence or by transferring energy to the reaction center to cause a charge separation, $\mathrm{ZP}_{680}^{+} \mathrm{Q}^{-}$. Here $\mathrm{Q}$ has been replaced with $Q_{1}$ and $Q_{2}$ as suggested to exist to explain $50 \mu$ s delayed light emission component in

* All delayed light yields are numbers of quanta emitted per quantum absorbed. They are obtained from areas under the DLE decay curves, not from amplitudes. chloroplasts treated with DCMU and hydroxylamine in light (Jursinic, 1977). The positive charge can stabilize in the $Z^{+} P_{680} Q_{1}^{-}$form or the charges can back react to give delayed light emission. In our working hypothesis, stabilization of the negative charge can also occur by conversion of state $\mathrm{Q}_{1}^{-}$to $\mathrm{Q}_{2}^{-}$; its influence is observable as a $50-60 \mu$ s lifetime decay component at $25^{\circ} \mathrm{C}$ in $\mathrm{NH}_{2} \mathrm{OH}$-treated chloroplasts. This same $50-60 \mu$ s component is observable in untreated chloroplasts at times greater than $120 \mu$ s when decay components due to more rapid stabilization reactions have become negligible. The correlation between discontinuities in membrane fluidity and this delayed light emission component suggests that this reaction may occur in a lipid environment. This is reasonable since the "primary" acceptor $Q$ is a quinone molecule (Stiehl and Witt, 1968; van Gorkom, 1974). This reaction has a measurable activation energy of about $200 \mathrm{meV}$ in pea chloroplasts (Fig. 5). The $k$ 's in Fig. 12 are the rate constants for the various reactions. The yield* of delayed light emission ( $\phi_{\mathrm{DLE}}^{6 \mathrm{HS}}$ ) assumed to be due to back reaction of $\mathrm{P}_{680}^{+}$ and $\mathrm{Q}_{1}^{-}$from the $\mathrm{ZP}_{680}^{+} \mathrm{Q}_{1}^{-}$form is given by the following expression, assuming $k_{-1}$ and $k_{-z}$ to be less than $k_{1}$ or $k_{\mathrm{z}}$ :

$$
\phi_{\mathrm{DLE}}^{6 \mu \mathrm{s}}=\phi_{\mathrm{r}}\left(\frac{k_{-1}}{k_{-1}+k_{\mathrm{Z}}}\right)
$$

where, for the $6 \mu$ s delayed light emission component, $k_{\mathrm{Z}}=1 / 6 \mu \mathrm{s}=1.67 \times 10^{5} / \mathrm{s}$ and $\phi_{\mathrm{DLE}}=2 \times 10^{-4}$ (Jursinic, 1977) and $\phi_{\mathrm{f}}=2.5 \times 10^{-2}$ (Latimer et al., 1956). Using these values, $k_{-1}$ is $1300 . k_{1}$ is calculated by the following equation:

$$
\phi_{f}=\frac{k_{f}}{k_{f}+k_{1}},
$$

neglecting small contributions from $K_{h}$ (rate of internal conversion), where $k_{f}=1 / 15 \mathrm{~ns}=6.67 \times 10^{7} / \mathrm{s}$, the reciprocal of the intrinsic fluorescence lifetime (Brody and Rabinowitch, 1957). $k_{1}$ is thus calculated to be $2.6 \times 10^{9} / \mathrm{s}$ which compares well with the trapping rate of approximately $2 \times 10^{9} / \mathrm{s}$ in algal cells calculated from fluorescence lifetime measurements (Mar et al., 1972). The free energy gap between the excited state of chlorophyll $a$ and the $Z P_{680}^{+} Q_{1}^{-}$form 


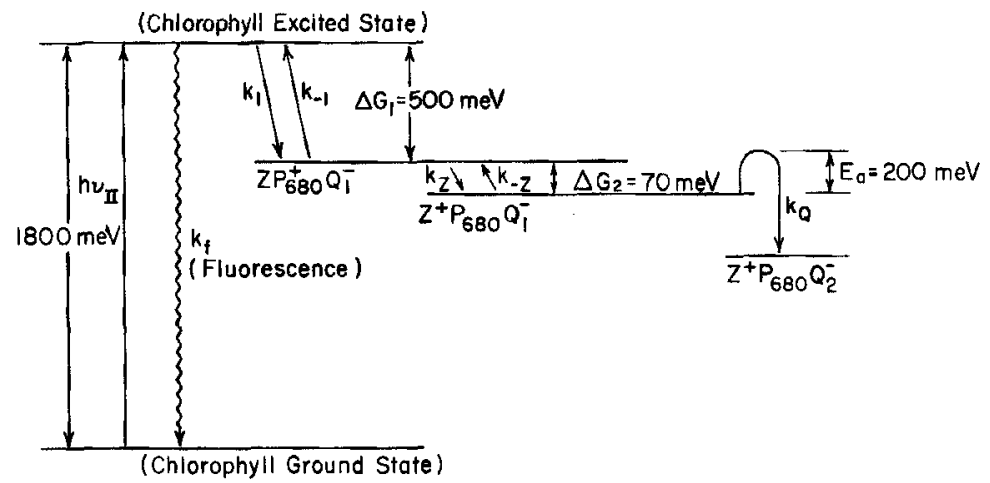

Figure 12. A proposed energy level diagram of microsecond time scale reactions in the Photosystem II reaction center. $h v_{\mathrm{II}}$, Photosystem II quantum; $\Delta G_{1}$ or $\Delta G_{2}$, free energy changes; $E_{a}$, activation energy; $k_{f}$, the fluorescence decay rate, and all other $k_{s}$, reaction rates; $Z$, the first secondary electron donor; $\mathrm{P}_{680}$, the reaction center chlorophyll $a$; and $\mathrm{Q}_{1}$ and $\mathrm{Q}_{2}$, two states of the "primary" electron acceptor.

of the Photosystem II reaction center is, according to the Boltzmann relationship:

$$
\frac{N_{1} k_{-1}}{N_{*} k_{1}}=\exp \left(\Delta G_{1} / k T\right)
$$

where, $N_{1} / N_{*}$ is the ratio of numbers of reaction centers to chlorophyll and is taken as $1 / 200, \Delta G_{1}$ is the free energy gap, $k$ is the Boltzmann constant, and $T$ is the absolute temperature. Using the calculated values for the variables in the above equation, $\Delta G_{1}$ is $500 \mathrm{meV}$. Since the chlorophyll excited state corresponds to about $1800 \mathrm{meV}$ of energy and $\Delta G_{1}=500 \mathrm{meV}$, then the $\mathrm{ZP}_{680}^{+} \mathrm{Q}^{-}$form of the reaction center has stored $1300 \mathrm{meV}$ of energy or about a $72 \%$ storage efficiency. This is in close agreement with the 68-73\% theoretical efficiency for light energy capture in photosynthesis (Duysens, 1958; Ross and Calvin, 1967). The $1300 \mathrm{meV}$ of energy is believed to be stored as an oxidation reduction potential difference between $\mathbf{P}_{680}^{+}$and $\mathbf{Q}_{1}^{-}$. The redox potential of $\mathrm{Q}_{1}^{-}$is uncertain, but values of $-35 \mathrm{mV}$ and $-270 \mathrm{mV}$ have been measured in chloroplasts (Cramer and Butler, 1969) and $-325 \mathrm{mV}$ in Photosystem II reaction center particles (Ke et al., 1976). The redox level of $\mathrm{P}_{680}^{+}$has not been measured, but must be at a higher potential than the oxygen evolving S-state. Kok et al. (1974) estimated its level to be $>\sim 820 \mathrm{mV}$. The above calculated value of $1300 \mathrm{meV}$ for the energy gap $\left(\Delta E^{\circ \prime}\right)$ allows us to calculate the redox potential of $P_{680}$. Assuming $Q_{1}$ to have the most negative redox potential of $-325 \mathrm{mV}$, the redox potential of $P_{680}$ would be as large as $0.975 \mathrm{eV}$, and assuming $Q_{1}$ to have the most positive redox poten- tial $(-35 \mathrm{mV})$, this is reduced to $1.265 \mathrm{eV}$. Thus, we can safely assume that the redox potential for $P_{680}$ is in the range of 1.0 to $1.3 \mathrm{eV}$-much more positive than $0.8 \mathrm{eV}$ for $\mathrm{H}_{2} \mathrm{O} / \mathrm{O}_{2}$ couple.

The yield of delayed light emission from $50-60 \mu \mathrm{s}$ component can be written as:

$$
\phi_{\mathrm{DLE}}^{\mathrm{SO}}=\phi_{\mathrm{DLE}}^{\mathrm{\sigma \mu \textrm {s }}} \frac{k_{-\mathrm{Z}}}{k_{-Z}+k_{\mathrm{Q}}}
$$

where $k_{\mathrm{Q}}$ is the reciprocal of this reaction lifetime or $2 \times 10^{4} / \mathrm{s}$ and $\phi_{\mathrm{DLE}}^{50_{\mathrm{HE}}}=1 \times 10^{4}$ (Jursinic, 1977). Using these values, $k_{-z}$ is $1 \times 10^{4} / \mathrm{s}$. Applying the Boltzman relationship, the free energy cap $\left(\Delta G_{2}\right)$ between the $\mathrm{ZP}_{680}^{+} \mathrm{Q}_{1}^{-}$and $\mathrm{Z}^{+} \mathrm{P}_{680} \mathrm{Q}_{1}^{-}$form of the reaction center is calculated to be $70 \mathrm{meV}$. The $\mathrm{Z}^{+} \mathrm{P}_{680} \mathrm{Q}_{1}^{-} \rightarrow \mathrm{Z}^{+} \mathrm{P}_{680} \mathrm{Q}_{2}^{-}$reaction has a $200 \mathrm{meV}$ activation energy (Fig. 12), but the back reaction rate constant for this reaction is not known, so the free energy change for this step is not calculated.

The free energy changes in this scheme have been calculated using measured yields and decay rates of delayed light emission and are consistent with measured and estimated redox levels of Photosystem II reaction center components. Energy pooling between reaction centers is not required to explain delayed light emission, which is consistent with a one quantum process having the observed I dependence (Fig. 1).

Acknowledgements-We thank Drs. Colin Wraight and Prasanna Mohanty for valuable discussions, and the National Science Foundation for financial support. PJ was supported through a research assistantship by the University of Illinois Research Board.

\section{REFERENCES}

Ames, G. F. (1968) J. Bacteriol. 95, 833-843.

Arnold, W. (1976) Proc. Natl. Acad. Sci. U.S. 73, 4502-4505.

Arnold, W. and J. R. Azzi (1968) Proc. Natl. Acad. Sci. U.S. 61, 29-35.

Arnold, W. and J. R. Azzi (1971) Photochem. Photobiol. 14, 233-240.

Arnold, W. and H. K. Sherwood (1957) Proc. Natl. Acad. Sci. U.S. 43, 105-114.

Arnon, D. (1949) Plant Physiol. 24, 1-15. 
Ashe, G. and J. Steim (1971) Biochim. Biophys. Acta 233, 810-814.

Bangham, A. D., J. DeGrier and G. D. Greville (1967) Chem. Phys. Lipids 1, 225-246.

Barratt, M. D., D. K. Green and D. Chapman (1969) Chem. Phys. Lipids 3, 140-144.

Bertsch, W. (1969) Progr. Photosynth. Res. 2, 996-1005.

Blazyk, J. and J. Steim (1972) Biochim. Biophys. Acta 266, 737-741.

Brody, S. S. and E. Rabinowitch (1957) Science 125, 555.

Chapman, D., J. Urbina and K. M. Krough (1974) J. Biol. Chem. 249, 2512-2521.

Cramer, W. A. and W. Butler (1969) Biochim. Biophys. Acta 172, 503-510.

Den Haan, G. A., L. N. M. Duysens and D. J. N. Egberts (1974) Biochim. Biophys. Acta 368, 409-421.

Desai, T. S., P. V. Sane and V. G. Tatake (1975) Photochem. Photobiol. 21, 345-350.

DeVault, D. and B. Chance (1966) Biophys. J, 6, 825-847.

Duysens, L. N. M. (1958) Brookhaven Symp. Biol. 11, 10-23.

Duysens, L. N. M., G. A. Den Haan and J. A. Van Best (1974) In Proceedings of the Third International Conference on Photosynthesis Research (Edited by M. Avron), pp. 1-12. Elsevier, Amsterdam.

Fleischman, D. (1971) Photochem. Photobiol. 14, 277-286.

Fleischman, D. (1974) Photochem. Photobiol. 19, 59-68.

Gaffney, B. J. (1974) In Methods in Enzymology 32B (Edited by S. Fleischer and L. Packer), pp. 161-197. Academic Press, New York.

Gaffney, B. J. (1975) Proc. Natl. Acad. Sci. U.S. 72, 664-668.

Govindjee and E. Rabinowitch (1960) Biophys. J. 1, 73-89.

Gräber, P. and H. T. Witt (1974) In Proceedings of the Third International Congress on Photosynthesis Research (Edited by M. Avron), pp. 951-956, Elsevier, Amsterdam.

Hess, J. T. H. and A. A. Benson (1968) Biochim. Biophys. Acta 150, 676-685.

Hsung, J., L. Huang, D. J. Hoy and A. Haug (1974) Can. J. Biochem. 52, 974-980.

Isaakidou, J. and G. Papageorgiou (1975) Arch. Biochem. Biophys. 168, 266-272.

Jones, L. W. (1967) Proc. Natl. Acad. Sci. U.S. 58, 75-80.

Junge, W. and H. T. Witt (1968) Z. Naturforsch. 23b, 244-254.

Jursinic, P. (1977) Ph.D. Thesis, University of Illinois at Urbana-Champaign.

Jursinic, P. and Govindjee (1972) Photochem. Photobiol. 15, 331-348.

Jursinic, P. and Govindjee (1977) Biochim. Biophys. Acta, in press.

Jursinic, P., Govindjee and C. Wraight (1977) Photochem. Photobiol., submitted for publication.

Ke, B., F. M. Hawkridge and S. Sahu (1976) Proc. Natl. Acad. Sci. U.S. 73, 2211-2215.

Kok, B., R. Radmer and C. F. Fowler (1974) In Proceedings of the Third International Congress on Photosynthesis Research (Edited by M. Avron), pp. 485 496, Elsevier, Amsterdam.

Kratz, W. A. and J. Myers (1955) Am. J. Bot. 42, 282 287.

Laine-Böszörmenyl, M., G. Paillotin, P. Fallot and E. Roux (1972) Photochem. Photobiol. 15, $139-156$.

Latimer, P., T. T. Bannister and E. Rabinowitch (1956) Science 124, 585.

Lavorel, J. (1969) Progr. Photosynth. Res. 2, 883-898.

Lavorel, J. (1971) Photochem. Photobiol. 14, 261-275.

Lavorel, J. (1975) In Bioenergetics of Photosynthesis (Edited by Govindjee), pp. 223-317. Academic Press, New York.

Lyons, J. and J. Raison (1970) Comp. Biochem. Physiol. 37, 405-411.

MacKinney, G. (1941) J. Biol. Chem. 140, 315-322.

Malkin, S. and H. Hardt (1973) Biochim. Biophys. Acta 305, 292-301.

Mar, T. and Govindjee (1971) Biochim. Biophys. Acta 226, 200-203.

Mar, T., Govindjee, G. S. Singhal and H. Merkelo (1972) Biophys. J. 12, 797-808.

Mathis, P., J. Haveman and M. Yates (1976) Brookhaven Symp. Biol. 28, 267-277.

Mauzerall, D. (1972) Proc. Natl. Acad. Sci. U.S. 69, 1358-1362.

Mauzerall, D. (1976) Biophys. J. 16, 87-91.

McMurchie, E., J. K. Raison and K. Cairncross (1973) Comp. Biochem. Physiol. 44B, 1017-1026.

Murakami, S. and L. Packer (1970) J. Cell. Physiol. 47, 332-351.

Murata, N. and D. C. Fork (1975) Plant Physiol. 56 791-796.

Murata, N., J. H. Troughton and D. C. Fork (1975) Plant Physiol. 56, 508-517.

Raison, J. K. (1973) J. Bioenergetics 4, 285-309.

Raison, J. K., J. Lyons, R. Melhorn and A. Keith (1971) J. Biol. Chem. 246, 40364040.

Raison, J. K. and E. McMurchie (1974) Biochim. Biophys. Acta 363, 135-140.

Reinert, J. and J. Steim (1970) Science 168, 1580-1582.

Ross, R. T. and M. Calvin (1967) Biophys. J. 7, 595-614.

Sackmann, E., H. Träuble, H. Galla and P. Overath (1973) Biochemistry 12, 5360-5369.

Sane, P. V., T. S. Desai, V. G. Tatake and Govindjee (1977) Photochem. Photobiol. 26, 33-39.

Shneyour, A., J. Raison and R. Smillie (1973) Biochim. Biophys. Acta 292, 151-161.

Shuvalov, V. A. and F. F. Litvin (1969) Molek. Biol. U.S.S.R. 3, 45-56.

Stacy, W. T., T. Mar, C. E. Swenberg and Govindjee (1971) Photochem. Photobiol. 14, 197-219.

Steim, J., M. Tourtellote, J. Reinert, R. McElhaney and R. Radmer (1969) Proc. Natl. Acad. Sci. U.S. 63, 104-109.

Stiehl, H. and H. T. Witt (1968) Z. Naturforsch. 23b, 220-224.

Strehler, B. and W. Arnold (1951) J. Gen. Physiol. 34, 809820.

Sweetser, P. B., C. W. Todd and R. T. Hersch (1961) Biochim. Biophys. Acta 51, 509-518.

Tollin, G. and M. Calvin (1957) Proc. Natl. Acad. Sci. U.S. 43, 895-908.

Tollin, G., E. Fujimori and M. Calvin (1958) Proc. Natl. Acad. Sci. U.S. 44, 1035-1047.

Torres-Pereira, J., R. Mehlhorn, A. Keith and L. Packer (1974) Arch. Biochem. Biophys. 160, 90-99. Tourtellottc, M., D. Breton and A. Keith (1970) Proc. Natl. Acad. Sci. U.S. 66, 909-916. 
Van Gorkom, H. (1974) Biochim. Biophys. Acta 347, 439-442. Weaver, E. C. and H. E. Weaver (1969) Science 165, 906-907.

Wisnieski, B., J. Parkes, Y. Huang and F. Fox (1971) Proc. Natl. Acad. Sci. U.S. 71, 4381-4385. Yamamoto, Y. and M. Nishimura (1976) Plant Cell Physiol. 17, 11-16.

Zankel, K. (1971) Biochim. Biophys. Acta 245, 373-385.

Zickler, A. and H. T. Witt (1976) FEBS Lett. 66, 142-148.

Zilinskas, B. A. and Govindjee (1976) Z. Pflanzenphysiol. 77, 302-314. 